\title{
How Wisdom Engages the Possible
}

Mane Kara-Yakoubian (mkarayak@uwaterloo.ca), Amanda Rotella (arotella@uwaterloo.ca), Anna Dorfman (anna.dorfman@uwaterloo.ca), Igor Grossmann (igrossma@uwaterloo.ca) University of Waterloo, Waterloo, Ontario, Canada

\begin{abstract}
Wisdom has been a central theme in the philosophical inquiry of the human experience for centuries, with the earliest written teachings dating back to the ancient Egyptian vizier, Ptahhotep 25-24 century BCE. The virtue of wisdom has been attributed to the great deities of various cultures and mythologies (e.g., Anahit of Armenia, Athena of Greece), and a quality humankind is encouraged to embody millennia later. In more recent decades, psychological scientists have begun to study the concept of wisdom, exploring characteristics of a wise person as well as meta-cognitive processes and moral aspirations involved in wise decision making. At the core of wisdom is the recognition and acceptance that for any given issue there are different possible perspectives, interests, contexts, and outcomes, as well as the willingness to consider and take into account these different possibilities when working through the issue. This chapter reviews the psychological study of wisdom, with a focus on the conceptual and empirical construct of wisdom as it relates to the possible.
\end{abstract}

Keywords: wisdom, wise reasoning, metacognition, moral aspirations 


\section{Defining wisdom}

Greek philosophers viewed wisdom as a way of understanding the world (Durant, 1926). To philosophers like Plato and Aristotle, wisdom was one of the most fundamental human virtues, a means of contemplating truth and guiding human conduct (Adler, 1952). Though this perspective dominated Western philosophy for hundreds of years (Birren \& Svensson, 2005), the conceptualization of wisdom evolved throughout history, leading to numerous and culturally diverse definitions of wisdom (Kung \& Grossmann, 2020). This presented a challenge to its empirical study, because while the plurality provided rich roots for empirical investigation, it also created conceptual ambiguity among researchers regarding the components that comprise such a complex psychological construct, with different researchers prioritizing different philosophical accounts in their conceptualization of wisdom (Grossmann et al., 2020b).

In lay terms, wisdom has many definitions, ranging from knowledge drawn from traumatic life experiences and personal growth, to intelligence, and rationality (Staudinger \& Glück, 2011). Within psychology, some scholars have studied wisdom from a person-centric perspective (e.g., Ardelt, 2003), while others have argued that wisdom can vary based on context (e.g., Grossmann et al., 2016; Grossmann et al., 2020a; Staudinger \& Baltes, 1996). Early psychological studies took a person-centric conceptualization of wisdom, where wisdom was characterized as a stable trait that an individual possessed (Birren \& Svensson, 2005). According to this account, people portray consistent and stable levels of wisdom across time and situations (e.g., 'a wise or unwise person;' Webster, 2007). In other words, wisdom is a trait that one either possesses or does not possess, reducing the notion of wisdom to (often) immutable characteristics of an individual. Recent empirical investigations take a broader approach. Although there is a moderate stability in people's tendency to deploy wisdom in reasoning (e.g., 
metacognitive processes that lead to wisdom), there are also considerable within-individual differences in how much people use wise reasoning, which varies according to context (Brienza et al., 2018; Grossmann et al., 2016; 2019). Thus, the degree to which a person engages in wise reasoning can differ across time and situations, with certain contexts facilitating wisdom while other situations constrain it. For example, recent work has found that people use more wise reasoning when they are around others (Grossmann et al., 2016), when they take others' perspectives (Kross \& Grossmann, 2012), or in relationships they care more about (Rotella \& Grossmann, in preparation).

To overcome the operationalization heterogeneity of wisdom in the social sciences (Staudinger \& Glück, 2011), leading scholars in this area of research established a common wisdom model (CWM), which includes moral, social, and cognitive approaches to wisdom, and provides a clear and overarching conceptualization of wisdom as a psychological construct (Grossmann et al., 2020b). The CWM is especially useful to understand wisdom from a socialsciences perspective. According to this model, wisdom is defined as "morally-grounded excellence in social-cognitive processing," highlighting two elements which are most characteristic to the construct: metacognition and moral aspirations (Grossmann et al., 2020b). Metacognition refers to higher-order thinking; in other words, thinking about and regulating one's thought-processes, cognitions, emotions and motives (Dunlosky \& Metcalfe, 2008). In the context of wisdom, metacognitive processes allow people to step back from a situation (e.g., the problem they are considering at the moment) to assess, evaluate, and adapt their approach, taking into consideration things like "what is my goal?", "is the current approach working?" and "what are the consequences of this approach?" (Grossmann et al., 2020b). Though not an exclusive list, the CWM encompasses the following metacognitions as central to wise reasoning: (1) 
context-adaptability; (2) epistemic humility; (3) integration of diverse viewpoints; and (4) perspectivism. Context-adaptability involves recognizing that contexts can change, and maintaining an open mind about such possible changes. It could present as searching for different solutions as a situation evolves, or considering alternative possible ways in which a situation could unfold (Grossmann, 2017; Grossmann \& Dorfman, 2019). Epistemic humility involves recognizing the limits of one's knowledge. This can manifest as questioning whether one's existing opinion on an issue is correct, recognizing that one may be lacking relevant information, and actively searching for extraordinary circumstances prior to forming an opinion. Integration of diverse viewpoints involves searching for a compromise between competing perspectives and interests. This process can include identifying possible compromises, or searching for a solution that would bridge competing interests. Lastly, perspectivism involves maintaining an open mind toward the possibility that there are different viewpoints concerning a given situation. It could manifest as making an active effort to take others' perspectives, or seeking a variety of opinions on a matter prior to arriving at a conclusion.

The second foundation of the common wisdom model concerns moral aspirations, implying that wisdom meta-cognitions have to be morally grounded. The notion that these metacognitive processes are morally grounded means that wisdom guides individuals to make decisions that promote the common good and well-being of others (Grossmann, 2017; 2020). The moral component of wisdom encompasses balancing self- and other-oriented interests, the pursuit of truth (vs. dishonesty), and an orientation toward shared humanity (i.e., recognizing we all share a common human experience regardless of group memberships; Grossmann et al., 2020b). Importantly, according to the CWM, wisdom-related metacognitive processes and moral aspirations work as a unit; these metacognitions without moral aspirations would be more 
descriptive of a sociopath than a wise person (Grossmann, 2020; Sternberg, 1998), as the fundamental reasoning processes of a sociopath would be focused on the self in isolation of others, rather than considering how one's actions are integrated into a broader context. Relatedly, moral aspirations without metacognition would simply be abstract concepts that would be difficult to implement. For example, to effectively pursue the truth, one would need to engage in perspectivism (e.g., maintaining an open mind about different possible viewpoints) and intellectual humility (e.g., acknowledging the limits of their own knowledge).

Notably, wisdom as conceptualized by the CWM is not fully explained by other conceptually related constructs (Grossmann et al., 2020b). Wisdom is not merely intelligence: in examining the relationship between intelligence (IQ) and wisdom, scholars suggest that while a certain level of IQ is necessary for wisdom, in that it facilitates cognitive processes, it is not sufficient to achieve wisdom. Moreover, IQ does not consistently predict the moral aspects of wisdom and only weakly predicts performance on tasks assessing the various features of wisdom (e.g., Grossmann et al., 2020b). Wisdom is also distinct from rationality, with empirical work showing that wisdom and rationality share only a weak relation (Brienza et al., 2018). And though some scholars have suggested that wisdom and emotional intelligence (i.e., the ability to perceive, understand, express, manage, and use emotions; Mayer \& Salovey, 1997) are conceptually the same (Zacher et al., 2013), both lay perceptions of wisdom and wisdom scholars tend to contradict this suggestion (Grossmann et al., 2020b). In a study evaluating short statements associated with wisdom, participants perceived that wise people are equally capable of problem solving and reasoning as intelligent people, however, wise people also had sagacity_which are interpersonal skills associated with knowing when to listen to others, having flexibility in interactions and relationships, and balancing long- and short-term consequences 
(Sternberg, 1985). Moreover, in a recent survey among experts of the Wisdom Task Force which explore this idea, none of the experts viewed emotional intelligence alone as a sufficient factor for wisdom. That is not to say that emotional intelligence is unrelated to wisdom. In fact, many experts view emotional intelligence as a pre-requisite for wisdom, however, they argue that these are two distinct constructs (Grossmann et al., 2020b). Similarly, most wisdom experts identified perspective-taking (i.e., "the capacity to recognize and coordinate the differences in people's perspectives," Baltes \& Staudinger, 2000) to be a necessary component of wisdom, but not sufficient on its own to capture the entire wisdom construct (Grossmann et al., 2020b).

\section{Wisdom and the possible}

Although wisdom is desirable across many contexts, it is particularly relevant in social relationships and social conflicts (Grossmann et al., 2020a; Grossmann \& Dorfman, 2019). While relationships are an integral part of the human experience, maintaining them requires effort. Interpersonal conflicts can arise, calling for one or both parties to keep an open mind, consider different possible solutions, and reach a compromise that maximizes both parties' interests. In other words, one would need wisdom to effectively sustain relationships. Consider the following scenario:

A person at the department where I work is angry at me over something that isn't my fault. It is actually another person's fault for not communicating information with them. I feel stuck in the middle and like no one will take responsibility. I just tried to defend myself when the angry person came in and talked about the situation. I explained that the head supervisor had told me that they wanted to communicate with this person. I promised to avoid miscommunications in the future. Ifeel annoyed and attacked because it's not my responsibility to play their office politics games. 
Many of us can relate to a conflict similar to the one highlighted above. How might one deal with such a situation? Recall that wisdom involves taking others' perspectives, placing a problem into a broader context, realizing the limits of one's knowledge, and integrating these ideas (Grossmann, 2017; 2020). By engaging in these metacognitive processes, people interact with the possible - that is, they deliberate about alternate possibilities, which would have otherwise been constrained without using wise reasoning processes. A person dealing with the above situation could entertain the possible by double-checking if their formed opinion of what occurred is in fact correct. For example, is it true that this "other person" did not communicate the pertinent information? Are there extraordinary circumstances that could explain why this information was not passed on to the appropriate people? One might also consider taking the perspective of the others involved, prior to forming a conclusion about the given event. In a conflict such as this, wisdom would allow one to approach the situation with a focus on the "big picture" (Grossmann \& Dorfman, 2019; Grossmann et al., 2016), instead of concentrating on little details that could misconstrue the event or misjudge those involved. Deploying wisdomrelated meta-cognitive considerations in such a conflict would facilitate the consideration of a variety of possibilities in terms of understanding what occurred and how the situation might further unfold.

In fact, wise reasoning has been related to many constructs that facilitate engagement with the possible. Wise reasoning has a moderate positive relationship to crystallized intelligence (e.g., Grossmann et al., 2013; Staudinger, Lopez, \& Baltes, 1997; Staudinger et al., 1998) which can allow people to relate current experiences to more accumulated knowledge, facts, and skills. Wisdom has also been related to personality constructs, where people who used more wisdom were also more open to experience, agreeable, and less neurotic (Brienza et al., 2017; Huynh et 
al., 2017; Kunzmann \& Baltes, 2003; Levenson et al., 2005; Mickler \& Staudinger, 2008;

Webster et al., 2014). People who are more open to experience, have a larger active imagination, greater aesthetic sensitivity, are more attentive to feelings, have a preference for variety, and have greater intellectual curiosity (Costa \& McCrae, 1992), all of which are characteristics that allow people to engage in more experiences and possibilities. Agreeableness is a personality construct associated with being kind, sympathetic, cooperative, warm, and considerate (Costa \& McCrae, 1992), which also facilitates perspective taking and integrating perspectives - two wise characteristics that enable cognitive engagement with alternate possibilities. On the flipside, people who score high on neuroticism have greater anxiety, worry, fear, anger, frustration, envy, and loneliness, and are more likely to interpret ordinary situations as threatening (Costa \& McCrae, 1992). These characteristics constrain engagement with alternative possibilities, and instead are associated with less cognitive flexibility (Murdock et al., 2013). Likewise, wise reasoning is associated with greater emotional diversity, emotional regulation (Grossmann et al., 2019a; 2019b; Grossmann et al., 2016), and interest and inspiration (Kunzmann \& Baltes, 2003). Thus, wise reasoning is associated with cognitive and personality characteristics that enhance engagement with the possible.

Wisdom further facilitates engagement with the possible for large-scale and important social issues (Grossmann \& Brienza, 2018; Sternberg, 1998). In recent years, we have seen the devastating consequences of climate change, observed terrorism in various parts of the world, and lived through a global pandemic. Circumstances such as these require us to deliberate on what is possible, in both considering how a situation may unfold, and ways of resolving it. Wisdom facilitates this. For example, during a pandemic, nations would benefit from wise leadership (Grossmann \& Dorfman, 2019). This could look like national leaders maintaining an 
open mind of how the trend of positive cases may evolve throughout the year, and searching for different solutions accordingly (context-adaptability). In fact, leadership learning has been associated with greater wisdom (Yang, 2014). This could also include maintaining an open mind about the various viewpoints offered by experts in different fields (e.g., health, economics) and integrating these prior to making any decisions (perspectivism). Here, wise leadership could also manifest as acknowledging that one does not have all the answers and could be lacking relevant information (epistemic humility). As well, it could entail searching for a solution that maximizes the number of interests satisfied (e.g., for students, elders, business owners; integration of diverse viewpoints). As established previously, wisdom is rooted in morality; as such, wise leadership during a global pandemic could look like recognizing that all humans share a common fate regardless of their country of residence, and thus collaborate internationally to discover a vaccine (shared humanity). Wisdom in this context would enable leaders to consider the different possible ways in which the pandemic could evolve and the possible ways in which it would be best addressed.

In addition to identifying and considering different perspectives and possibilities, wisdom is also concerned with balance and integration. This component of wisdom is necessary to avoid infinite deliberation on possible alternatives. Integration of alternatives becomes particularly relevant in situations in which one must decide how to act. To illustrate this point, consider the ongoing COVID-19 pandemic. Government officials and their consultants do not have an infinite amount of time or resources to consider all of the ways in which it could unfold and develop mitigation strategies in accordance with each and every possibility. A delay in decision-making can have catastrophic consequences (e.g., thousands of preventable deaths). Faced with multiple alternatives in such a situation requires consideration of how to balance and integrate them. 


\section{Fostering wisdom}

Using wise reasoning has many benefits. Wisdom is associated with greater life satisfaction, greater longevity, less negative emotions, less depressive reflection, and can promote prosociality (Grossmann et al., 2013; 2017). Thus, to facilitate engagement with alternate possibilities, perspectives, and contexts - that is, to consider the possible - we must first understand how to facilitate and promote the use of wise reasoning.

Recent research suggests that self-distancing by taking a third person's perspective - i.e., considering a conflict as a distanced or uninvolved observer - facilitates wisdom (Dorfman, Moscovitch, \& Grossmann, 2020; Kross \& Ayduk, 2011; Kross \& Grossmann, 2012). In a series of studies, Grossmann \& Kross (2014) examined the role of self-distancing on wise reasoning. Participants were randomly assigned to reflect on a situation in which their partner cheated on them, or their best friend's partner cheated on their friend, and to reason about how the relationship would unfold moving forward. They found that participants assigned to the "other" condition (i.e., thinking about their friend's relationship) scored higher on wise reasoning, confirming that self-distancing from a situation can facilitate greater wisdom. In a follow-up study, an infidelity situation was presented once more. This time, participants were assigned to one of four condition, instructing them to either: a) consider this to be their own problem from an immersed perspective (self-immersed), b) consider this to be a friend's problem from an immersed perspective (other-immersed), c) consider this to be their own problem from a distanced perspective (self-distanced), or d) consider this to be a friend's problem from a distanced perspective (other-distanced). Self-distancing was manipulated via the use of firstperson or third-person pronouns when reflecting on the conflict (e.g., "I am feeling..." vs. "She/he is feeling..."). The authors found that participants in the other-immersed and other- 
distanced conditions engaged in greater wise reasoning than those in the self-immersed condition. Further, participants in the self-distanced condition portrayed greater levels of wise reasoning than those in the self-immersed condition. Notably, those assigned to the otherdistanced and other-immersed conditions did not differ from those assigned to the self-distanced condition in their wise reasoning, demonstrating that distancing of any manner (i.e., otherimmersed, other-distanced, self-distanced), promotes similar levels of wise reasoning. In a third study, the researchers explored whether age plays a role in wisdom. Contrary to the popular belief that "with age comes wisdom" they found no age differences in wise reasoning among younger or older adults, and further, that the self-distancing intervention worked equally effectively for both age groups. These findings confirm that no matter one's age, taking the perspective of a distanced observer can inspire greater wise metacognitions, allowing one to explore the possible. This is consistent with similar research, such that perspective taking enhances creativity, and in turn, exploring what is possible (Glăveanu, 2020).

Additionally, engaging in future-oriented perspectives can increase wise thinking. For example, reframing how someone reflects on a situation (i.e., "how would I feel about this in the future" versus "how do I feel about this now") can help people approach conflicts more wisely (Huynh et al., 2016; Kross et al., 2012; Robson, 2019). Further, in the context of relationship conflict, creating temporal space between the self and situation can promote greater insight, greater forgiveness, and greater relationship well-being, while reducing partner blame and negative emotions about the relationship (Huynh et al., 2016).

Another effective method of self-distancing is the use of third-person language (i.e., "What should she/he do about this?" versus "What should I do about this?"). Engaging in egodecentering has shown to increase wise reasoning in hypothetical scenarios (Grossmann \& 
Kross, 2014; Kross \& Grossmann, 2012), and in autobiographical real-life experiences

(Grossmann et al., 2019b). The use of third-person language was recently examined as a means to prospectively facilitate wisdom. In a recent micro-longitudinal study, participants wrote a daily diary entry over a 1-month span; they were instructed to record their reflections of a noteworthy daily experience using a first- or third person perspective (Grossmann et al., in press). The researchers found significant increase in wise metacognitions in participants' reflections on a recent personal social conflict after (vs. before) the third-person reflections intervention, a promising sign that one could implement a specific technique such as journaling using third-person language to promote wise reasoning when dealing with a new conflict. These findings suggest that reframing how someone thinks about a situation, problem, or conflict can promote greater wisdom and the exploration of various possibilities.

\section{Conclusion}

We have discussed the conceptualization of wisdom, highlighting that the metacognitions encompassed by the common wisdom model (i.e., context-adaptability, perspectivism, epistemic humility, and integration of diverse viewpoints) are morally grounded, guiding individuals to make decisions that promote a common good. Importantly, we established that at the very core of wisdom is the recognition and acceptance of the possible, and reviewed empirical findings of how wisdom is associated with greater possibilities. Whether it is the consideration of different perspectives, viewpoints, interests, solutions, or outcomes when reflecting on a given situation, wisdom allows us to explore the possible. 


\section{References}

Adler, M. J. (1952). The great ideas: A syntopicon of great books of the western world. (Vol. 2). Chicago: William Benton Publisher.

Ardelt, M. (2003). Empirical assessment of a three-dimensional wisdom scale. Research on Aging, 25(3), 275-324. https://doi.org/10.1177/0164027503025003004

Ardelt, M., \& Jeste, D. V. (2018). Wisdom and hard times: The ameliorating effect of wisdom on the negative association between adverse life events and well-being. The Journals of Gerontology: Series B, 73(8), 1374-1383. https://doi.org/10.1093/geronb/gbw137

Baltes, P. B., \& Smith, J. (2008). The fascination of wisdom: Its nature, ontogeny, and function. Perspectives on Psychological Science, 3(1), 56-64. https://doi.org/10.1111/j.1745$\underline{6916.2008 .00062 . x}$

Baltes, P. B., \& Staudinger, U. M. (2000). Wisdom: A metaheuristic (pragmatic) to orchestrate mind and virtue toward excellence. American Psychologist, 55(1), 122136. https://doi.org/10.1037/0003-066X.55.1.122

Birren, J. E., \& Svensson, C. M. (2005). Wisdom in history. A Handbook of Wisdom: Psychological Perspectives, 3-31.

Brienza, J. P., Kung, F. Y. H., Santos, H. C., Bobocel, D. R., \& Grossmann, I. (2018). Wisdom, bias, and balance: Toward a process-sensitive measurement of wisdom-related cognition. Journal of Personality and Social Psychology, 115(6), 1093-

\section{6. https://doi.org/10.1037/pspp0000171}

Brugman, G. M. (2000). Wisdom: Source of narrative coherence and eudaimonia. Delft, The Netherlands: Eburon. 
Dorfman, A., Moscovitch, D. A., \& Grossmann, I. (In press). Pathways from adversity to wisdom. In F. J. Infurna \& E. Jayawickreme (Eds.). Redesigning Research on Post-Traumatic Growth: Challenges, Pitfalls and New Directions. New York: Oxford University Press.

Dunlosky, J., \& Metcalfe, J. (2008). Metacognition. Sage Publications.

Durant, W. (1961). Story of Philosophy. New York: Simon and Schuster.

Glăveanu, V. P. (2020). A sociocultural theory of creativity: Bridging the social, the material, and the psychological. Review of General Psychology, 24(4), 335-354.

Glück, J., Sternberg, R. J., \& Nusbaum, H. C. (2019). Not today, and probably not tomorrow either: Obstacles to wisdom and how we may overcome them. In Applying Wisdom to Contemporary World Problems (pp. 445-464). Cham: Springer International Publishing. https://doi.org/10.1007/978-3-030-20287-3_16

Grossmann, I., Kung, F. Y. H., \& Santos, H. C. (2019b). Wisdom as state versus trait. In R. J. Sternberg \& J. Glück (Eds.), The Cambridge handbook of wisdom (p. 249-273). Cambridge University Press. https://doi.org/10.1017/9781108568272.013

Grossmann, I. (2020). The science of wisdom. AEON. https://aeon.co/essays/how-psychological$\underline{\text { scientists-found-the-empirical-path-to-wisdom }}$

Grossmann, I., Brienza, J. P., \& Bobocel, D. R. (2017). Wise deliberation sustains cooperation. Nature Human Behaviour, 1(3), 1-6. https://doi.org/10.1038/s41562-017-0061

Grossmann, I., \& Brienza, J. P. (2018). The strengths of wisdom provide unique contributions to improved leadership, sustainability, inequality, gross national happiness, and civic discourse in the face of contemporary world problems. Journal of Intelligence, 6(2), 22. https://doi.org/10.3390/jintelligence6020022 
Grossmann, I., \& Dorfman, A. (2019). Wise reasoning in an uncertain world. In Applying wisdom to contemporary world problems (pp. 51-79). Palgrave Macmillan, Cham. https://doi.org/10.1007/978-3-030-20287-3 3

Grossmann, I., Dorfman, A., \& Oakes, H. (2020a). Wisdom is a social-ecological rather than person-centric phenomenon. Current Opinion in Psychology, 32, 66-71. https://doi.org/10.1016/j.copsyc.2019.07.010

Grossmann, I., Dorfman, A., Oakes, H., Santos, H. C., Vohs, K. D., \& Scholer, A. A. (in press). Training for wisdom: The distanced self-reflection diary method, Psychological Science. https://doi.org/10.31234/osf.io/a5fgu

Grossmann, I., Gerlach, T. M., \& Denissen, J. J. (2016). Wise reasoning in the face of everyday life challenges. Social Psychological and Personality Science, 7(7), 611-622. https://doi.org/10.1177/1948550616652206

Grossmann, I., \& Kross, E. (2014). Exploring Solomon's paradox: Self-distancing eliminates the self-other asymmetry in wise reasoning about close relationships in younger and older adults. Psychological Science, 25(8), 1571-1580.

https://doi.org/10.1177/0956797614535400

Grossmann, I., Na, J., Varnum, M. E. W., Kitayama, S., \& Nisbett, R. E. (2013). A route to wellbeing: Intelligence versus wise reasoning. Journal of Experimental Psychology: General, 142(3), 944-953. https://doi.org/10.1037/a0029560

Grossmann, I., Oakes, H., \& Santos, H. C. (2019b). Wise reasoning benefits from emodiversity, irrespective of emotional intensity. Journal of Experimental Psychology: General, 148(5), 805-823. https://doi.org/10.1037/xge0000543 
Grossmann, I., Weststrate, N. M., Ardelt, M., Brienza, J. P., Dong, M., Ferrari, M., Fournier, M. A., Hu, C. S., Nusbaum, H. C. \& Vervaeke, J. (2020b). Wisdom science in a polarized world: Knowns and unknowns. Psychological Inquiry, 31(2), 1-31. https://doi.org/10.1080/1047840X.2020.1750917

Helson, R., \& Srivastava, S. (2002). Creative and wise people: Similarities, differences, and how they develop. Personality and Social Psychology Bulletin, 28(10), 1430-1440. https://doi.org/10.1177/014616702236874

Huynh, A. C., Yang, D. Y. J., \& Grossmann, I. (2016). The value of prospective reasoning for close relationships. Social Psychological and Personality Science, 7(8), 893-902. https://doi.org/10.1177/1948550616660591

Huynh, A. C., Oakes, H., Shay, G. R., \& McGregor, I. (2017). The wisdom in virtue: Pursuit of virtue predicts wise reasoning about personal conflicts. Psychological Science, 28(12), 18481856. https://doi.org/10.1177/0956797617722621

Kross, E., \& Ayduk, O. (2011). Making meaning out of negative experiences by self-distancing. Current Directions in Psychological Science, 20(3), 187-191. https://doi.org/10.1177/0963721411408883.

Kross, E., \& Grossmann, I. (2012). Boosting wisdom: Distance from the self enhances wise reasoning, attitudes, and behavior. Journal of Experimental Psychology: General, 141(1), 4348. https://doi.org/10.1037/a0024158

Kung, F. Y. H. \& Grossmann, I. (2020). Wisdom across cultures. In O. Braddick (Ed.), Oxford Research Encyclopedia of Psychology. New York: Oxford University Press. $\underline{\text { https://doi.org/10.1093/acrefore/9780190236557.013.586 }}$ 
Kunzmann, U., \& Baltes, P. B. (2003). Beyond the Traditional Scope of Intelligence: Wisdom in Action. American Psychological Association.

Mayer, J. D., \& Salovey, P. 1997. What is emotional intelligence? In P. Salovey \& D. J. Sluyter (Eds.), Emotional development and emotional intelligence: Educational implications: 3-31. New York: Basic Books.

Murdock, K. W., Oddi, K. B., \& Bridgett, D. J. (2013). Cognitive correlates of personality. Journal of Individual Differences, 34, 97-10. https://doi.org/10.1027/1614$\underline{0001 / a 000104}$

Plato. (2000). The Last Days of Socrates: Eythyphro, Apology, Crito, Phaedo. New York: Penguin.

Robson, D. (2019). Why speaking to yourself in the third person makes you wiser. AEON. https://aeon.co/ideas/why-speaking-to-yourself-in-the-third-person-makes-you-wiser

Staudinger, U. M., \& Baltes, P. B. (1996). Interactive minds: A facilitative setting for wisdomrelated performance? Journal of Personality and Social Psychology, 71(4), 746762. https://doi.org/10.1037/0022-3514.71.4.746

Staudinger, U. M., \& Glück, J. (2011). Psychological wisdom research: Commonalities and differences in a growing field. Annual Review of Psychology, 62, 215-241. https://doi.org/10.1146/annurev.psych.121208.131659

Sternberg, R. J. (1985). Implicit theories of intelligence, creativity, and wisdom. Journal of Personality and Social Psychology, 49(3), 607-627.

Sternberg, R. J. (1998). A balance theory of wisdom. Review of General Psychology, 2(4), 347365. https://doi.org/10.1037/1089-2680.2.4.347 
Webster, J. D. (2003). An exploratory analysis of a self-assessed wisdom scale. Journal of Adult Development, 10, 13-22. https://doi.org/10.1023/A:1020782619051

Webster, J. D. (2007). Measuring the character strength of wisdom. The International Journal of Aging and Human Development, 65(2), 163-183. https://doi.org/10.2190/AG.65.2.d

Zacher, H., McKenna, B., \& Rooney, D. (2013). Effects of self-reported wisdom on happiness: Not much more than emotional intelligence? Journal of Happiness Studies, 14(6), 1697-1716. https://doi.org/10.1007/s10902-012-9404-9 